\title{
Cultural Dimension of Food Safety in Universities
}

\author{
Tang Pingqiu ${ }^{1}$ Li Songyou ${ }^{1}$ Wang Yinghui ${ }^{2}$ \\ ${ }^{1}$ School of Public Policy and Management Studies, Guangxi University, \\ Nanning 530004, China \\ ${ }^{2}$ School of Environmental Studies, Guangxi University, Nanning 530004, China
}

\begin{abstract}
Nowadays food safety has become a hot topic in Chinese society. Research shows that to maintain food safety we cannot only rely on government supervision and legal penalties. The establishment of food safety culture is the final approach to this issue. For universities, the management of food safety is a complicated system. This paper tries to define food safety culture from four dimensions--material culture, regulatory culture, liability culture and consumption culture so as to further spread the concept of "building a healthy and safe campus" and offer approaches to establish food safety culture.
\end{abstract}

Keywords: university, food safety, cultural dimension

\section{Introduction}

The Eighteenth National Congress of the Communist Party of China put it "food is the first necessity of the people and food safety should be protected" and propose "to promote the development of socialist culture". Establishing food safety culture is crucial to create a sound environment for food safety. Over the past decade, China has always attached great importance to food safety. Chinese President Xi Jinping, Chinese Premier Li Keqiang and other leaders have made instructions:food safety is closely related to people's livelihood and it should be placed in the most important position. Local People's Congresses have continued to improve relevant laws and regulations. Food regulatory authorities have also strengthened supervision and attached greater importance to this end. In addition, China has carried out HACCP, ISO9001, ISO22000 and other food safety quality control standards and ultimately built a multidimensional prevention and control system. Although supervision and penalties for violations are enhanced, food safety incidents still occur frequently. Therefore, except for legal, system and technological approaches, the establishment of food safety culture is vital in this regard. If people's awareness on food safety is increased, many food safety accidents could be stopped before happening.

\section{Basic connotation of university food safety culture}

\subsection{Concept of university food safety culture}

In his Man On - Guiding Philosophy of Human Culture, German philosopher Cahill put forward the "intellectuals" of humanity hypothesis: organizational culture is the key factor for its 
development. Culture has broad sense and narrow sense. In a broad sense, it has four aspects: material, behavior, institution and spirit; the spirit culture is not only the highest level of the culture, but also, in a narrow sense, the essential and ideological concept of culture. The author believes that food safety culture in universities includes the concept of food safety regulation and institutions, food safety awareness and attitudes of consumers, and food production and responsibilities. It reflects the quality, attitudes and behavior of food safety culture $^{[1]}$.Therefore, the essence of building food safety culture in universities is that culture should exert an imperceptible influence on behavioral agents in this field for achieving food safety.

\subsection{The contents of food safety culture in universities}

To strengthen the establishment of food culture, firstly, all dimensions of food safety culture should be discussed. The contents of food safety culture is very abundant and it can be classified according to its extension and characteristics. The author believes that food safety culture in universities mainly consists of four aspects, as shown in figure 1:

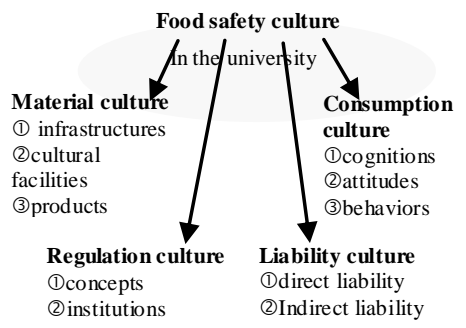

Fig 1 four dimensions of food safety culture

\subsubsection{Material culture of food safety}

The existence of culture is actually entrusted to material carriers in universities. Its representation and function are showed through a variety of tangible carriers. Thus, in reality, the production and operation characteristics and environmental factors have an impact on food safety culture. Therefore, we must first understand the current situation of food safety culture in universities from the perspective of material culture in order to guide safety management and practices.

(1) Production and operation facilities. Food production and operation facilities in universities and the environment are the external manifestation of safety culture. It directly determines consumer groups' intuitive feelings. Apparently, architectures and decoration of food production and operation facilities reflect operator's attitudes on food safety; the sanitary condition and arrangement of a canteen not only reflect the operator's quality of management and service, but also its safety concept to a certain degree. Therefore, food production and operation facilities and environment are part of food safety culture, which is the guarantee for the development of material culture.

(2)Cultural facilities of safe operation. Organization culture is manifested as organization climate, which is intervened in the purpose to serve the organization. In universities, carefully-refined banners, slogans and aphorisms promoting food safety, and food safety websites and manuals, are able to create culture atmosphere which has an imperceptible influence on people. What impresses people the most is the safety culture atmosphere, which is a force field, resulting in the surrounding subjects (as shown in figure 2). Therefore, the more concentrated the atmosphere, the wider impact and greater influence on people, and the better work on food safety. 


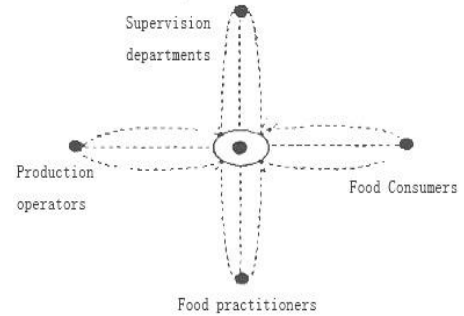

Fig 2 Cultural force field of food safety

(3) Food. Product embodies rich cultural connotations and to be familiar with the product is an important way to understand safety culture. From the nature of food, it carries the value of life . The attitude on food equals the attitude towards life. Thus, in terms of food safety culture, food bears the connotation of contract culture . High-quality goods can bring a certain degree of popularity and reputation, reflecting the culture of respect for human life. However, lowquality goods bring economic losses to consumers. They destroy and deprive the right of health and life of university consumers. In addition, food package, storage-life tips and qualified identification are reflected in the pursuit of food safety culture.

\subsubsection{Regulatory culture of food safety}

Regulatory culture of food safety includes the material and spiritual achievements of food safety supervision departments in the food safety supervision. It is a group culture which is formulated in the longterm regulation practice, with food safety thinking and spirit as the core, protected by food safety system, with ethical standards of food safety as the soft binding, material support of regulation of food safety as the basis, and supervision areas of food safety as the main space of activity, and the enhancement of supervision on food safety as the guiding ideology $y^{[2]}$. It includes two aspects : regulation concept and regulation system:

(1)Regulation concept .Scientific Outlook on Development puts people first. It is in line with the regulatory concept in universities because protecting food safety is the fundamental objective of scientific regulation. Universities should conscientiously sum up the existing experience on food regulation, fulfilling the concept of scientific supervision, such as people-oriented management, wholeprocess governance, risk governance, society governance, law-abiding governance, liability management, efficiency governance, comprehensive management and meticulous governance, so as to grasp the laws of governance for food safety. Apart from the concept of regulation, universities should focus on execution check-up and service concept, cost and benefit and so on. Scientific concept of regulation should be followed to improve the standards of food safety regulation.

(2) Regulatory system. North believes "Systems are the rules of the game of society. Normatively speaking, they create some artificial constraints for the relationship among people." Food safety could not be achieved without complete and reasonable regulatory systems. On the one hand, with or without inspection and supervision, operators should respect the seriousness of the system, and consciously implement some rules and regulations.On the other hand, system is not only regulators' culture, but also common culture. While paying attention to the external constraints of the food producers, we should consider their identification of psychological connotations with the systems so as to contribute to the pursuit of the same value. Therefore, through the inspection on the enforcement and recognition level of food safety regulatory system, you can examine the level of scientific supervision 
via analyzing content of the systems. In this way, we can be familiar with the value of regulatory authorities.

\subsubsection{Liability culture of food safety}

Management expert Peter Drucker said: the existence of any organization is not only for themselves but for the society. Food producers have no rights to avoid the obligation.For the first time Food Safety Law legislatively defines the responsibility system of food safety, with overall responsibility shouldered by local governments, regulatory authorities taking their respective responsibilities and the production company is primarily responsible for food safety ${ }^{[3]}$. Food producers are the first responsibility person of food safety. They should consciously abide by the requirements of food safety regulations, and actively carry out the responsibility of protecting food safety, reduce the number of unsafe food and accidents of food safety. Responsibility of food safety for consumers lies on enhancing the awareness of food safety, selecting safe food, monitoring and informing against illegal operators. Regulatory authorities should take effective measures to create regulations, standards and policies of food safety, and execute them, regulate behaviors of operators, protect the safety of food. Thus, fulfillment of liability culture of food safety is assured.

\subsubsection{Consumption culture of food safety}

Safety culture has three levels, in which the outer layer can be observed, including environment, system ceremonies and etc; the intermediate layer includes beliefs and values; and the basic sense is the intrinsic layer. Schein believes that, in fact, the basic sense can guide people's behaviors, telling members of the group how to observe, think and perceive things ${ }^{[4]}$. In Includes attitudes of safety,behaviors and etc.Therefore, knowledge of safety, attitudes and behaviors of consumers in universities are the individual variables affecting food safety culture, thus forming the fields of studies of food safety culture.

(1) Cognition of food safety. In 1871, Primitive Culture written by British Cultural historian Taylor put forward the narrow cultural theory, namely knowledge, belief of culture,morality, law, customs and a complex which is composed of capabilities and habits of any person as a member of society. It is suggested that consumer's cognition of food safety is an indispensable element of consumer culture. Indeed, the more ways to attain knowledge of food safety, the more comprehensive, the higher the level of cognition, suggesting food safety culture is more abundant and profound. There is no doubt that consumers desire to eat safe food and identify unsafe food. How to tackle problems of food safety, the key relies on their level of knowledge of food safety. Similarly, publicity and popularization of Food Safety Law is an important way to improve consumer's awareness of food safety, because it is the text vector of the modern food safety culture and the most systematic and authoritative expression.

(2) Attitudes on food safety. universities should pay attention to the establishment of food safety culture from the perspective of the consumer's attitude to food safety. First of all, people's attitudes towards something depend on the its significance to people, that is, the value of things has the magnitude, which can meet their own needs ${ }^{[5]}$. When food safety is closely related with their own interests, if they put more emphasis on food safety,food safety has an great impact on their health. Secondly, in view of the supervision of food safety, whether 
the businessmen are willing to cooperate is related to awareness training of their self-discipline and legitimate business. Finally, the fact that consumers are willing to learn more knowledge of food safety reflects concerns of their own health.

(3) Behavior of food safety. Food safety is closely related to eating habits of consumer groups. The more healthy eating habits are formed, the higher culture degree of food safety is formed. On food purchases, whether paying attention to the production date, shelf life and related certificate of inspection, whether buying the bulk food without mark of the production date and shelf life, whether being indifferent to problems of the food quality or beyond shelf life of food, whether preferring supermarkets, convenience stores or street hawkers, whether choosing school canteen or offcampus restaurants, all these habits reflect the concept of food safety held by the consumer in universities. Therefore, only advocating healthy eating habits, changing unsafe hygiene behaviors of food can we achieve the purpose of improving consumer health.

In short, the more knowledge about food safety, the more cautious towards safety, the better the behaviors become. In addition, we should create a campus atmosphere that people are concerned with food safety, bring changes to consumer groups' habits and ideology .

\section{The characteristics of the food safety culture}

\subsection{People-oriented management is more important than system management}

Food safety culture in universities is a "people-centered" management culture rather than "system-centric" management.
While "people-centered" management culture depends on organizational behavior norms, rules and regulations of the cognition, creating common value and psychological culture atmosphere for people, which could produce the sense of self-control and self-management to achieve internal and self-discipline. It changes "I do what they require" into "I do what I want to do" and mobilizes the initiative of people.Therefore, it is important to integrate "people-centered" management with "system-centric" management.

\subsection{Psychological care overwhelms physical means}

The traditional materialism depends excessively on the physical means, which lacks of the communication between main bodies. This way it generates the distrust among persons who will overlook the psychological factors on culture. The 16th Session of the 6th Plenary Session of the Central Committee of the Communist Party of China put forward the Decisions on Establishing Harmonious Socialist Society which emphasizes "We need to focus on promoting people's mental harmony, strengthening humane care and psychological counseling, guiding people to treat themselves, others and society correctly. Then they can deal with difficulties, setbacks and honor aright" and put forward the concept of psychological harmony ${ }^{[6]}$. In fact, promoting psychological harmony is a reflection of the implementation of psychological care. Psychological care is more effective than physical management means. On the one hand, it pays attention to guidance instead of mandatory requirements, through the establishment of mutual trust, mutual benefit and good interaction mechanism of psychological conflict to the realization of management objectives.On the other hand, it advocates 
to strengthen the food safety consensus and the sense of responsibility, and encourages stakeholders actively participate in this work to develop a comprehensive network with strict supervision.

\section{Methods of establishing food safety culture in universities}

\subsection{Valuing importance of material culture of food safety}

As emphasizing material culture is an indispensable part of food safety culture design, which can protect the consumers' physical and mental health in the campus. Firstly, pay attention to the improvement of the facilities in production and operation; normalize the architectural planning and design; definite the requirement of light range and ventilation to meet the standards the production safety. Meanwhile, update the interior and exterior decoration timely and maintain the production equipment and dining environment clean to reveal the content of safety culture base on the premise of processing the basic functions.Secondly, attach great importance to perfect cultural facilities and create a good safety culture atmosphere. The signs and aphorisms are nothing more than the food safety refinery, which can conduct the internalized safety awareness into the actors' way of thinking. Meanwhile, to achieve the unification of "form" and "spirit" of the culture, a long-term publicizing and tireless efforts to promote safety culture are needed.Finally, emphasize food quality. The quality of food is directly related to the health of consumers. It is an effective protection of safety culture development and prosperity, by requiring food production, strictly according to the safety production process to meet food safety standards, and depending on mature, healthy and technological achievement to safeguard consumers' physical and mental health.

\subsection{Grasping the food safety regulatory culture}

The key of grasping food safety regulatory culture is to uphold the scientific means of supervision, system and concept; to unify responsibilities, rights and interests of regulatory object; and to establish an open and flexible, efficient and effective regulatory system to ensure food safety. Meanwhile, being people-oriented, establish food safety regulatory concepts, and constantly enhance function of food regulatory culture radiation.

\subsubsection{Establishing food safety regulatory supervision cultural concepts}

(1)Adhere to hard and soft regulatory. The study found that hard-regulation refers to substantive supervision and management of regulatory authority, rather than the regulatory staying on the surface. In addition to formal regulatory authorities, soft regulation is implementing regulation of other participating subjects. Among the regulation departments, business sector and health supervision are substantial regulatory authorities. Exercising their regulatory functions and supervision rights are hard constraints. The multiregulatory departments actively involved in are soft constraints. In practice, hard regulation can achieve immediate effectiveness. But soft regulations often float on the surface, which requires a degree of system to protect them. To achieve mutual cooperation, mutual complement and improve the effectiveness of food safety supervision, the status and role of public opinion need to be improved, and social, democratic 
and administrative supervision need to be enhanced.

(2)Insist in soft and hard regulation. In order to ensure food safety, implementations of HACCP, ISO9001 and ISO22000 standards and enacted preventions and food safety system controls and laws are all means of hard constraints. But in fact, hard regulations are often with little success, and are always palliative. To improve the effectiveness of supervision, flexible means of restraint must be applied, that is to change the attitude of regulators to strengthen the persuasiveness; to eliminate the regulated psychological and behavioral distrust; to keep their obligations and responsibilities in mind and regulate behavior consciously. Therefore, to improve the effectiveness of supervision, and to form a good atmosphere of "everyone accept supervision, everyone consciously enforce supervision", rigid and flexible means of mutual cooperation is much needed.

\subsubsection{Constructing regulatory system of food safety culture}

The constantly improvement of food safety supervision level could not be achieved without the constraints of regulatory regimes. Firstly, standardize the management entities, improve access system, job training system and so on, which is conducive to fostering qualified food production business entities. Secondly, in view of consumers, smooth channels for complaints and to establish prizes of reporting mechanisms and etc. are conducive to enhancing consumers' food safety awareness and self-protection capabilities, and stimulating their interesting in participating in social supervision of food safety. Finally, for regulatory authorities, to establish a flexible emergency warning mechanism for timely treatment on food safety reports. When major food safety incident occurs, the related department needs to report to the leadership, and coordinate them to solve problems timely. And in the end, to integrate the food safety supervision work into the system target.

\subsection{Implementing the liability culture of food safety}

Food safety liability should play a guiding role of ideology and foster the shared responsibility as a basic project. On February 28, 2009, the 7th meeting of the NPC Standing Committee passed the Food Safety Law, marking China's food safety work going into a new stage. It identifies overall responsibility of local governments; regulatory authorities responsible for their own; the production company is the first responsibility person of the "three responsibilities" system. Firstly, implement the responsibility of the regulatory authorities. Regulatory authorities in accordance with the requirements of the government food safety regulations carry out food safety violation supervision to ensure food safety law implemented and enforced thoroughly. What's more,we need to further refine the accountability requirements, define person responsible security and strict accountability. Secondly, identify producers are the first responsibility person of food safety. In order to reduce unsafe food supply and food safety accidents, publicity and education can teach operators of production discipline, let them attach great important to food quality, and fulfill the responsibility of ensuring food security actively. Finally, implement of the supervision and responsibility of universities consumers to encourage multi-stakeholder oversight, and gradually form a good social atmosphere of "one for all, all for one". 


\subsection{Popularizing of food safety consumption culture}

Food Office of the State Council issued The Outline of the Food Safety Publicity and Education (2011-2015), requiring the popularity of food safety laws, regulations and scientific knowledge, and the rate of public awareness of food safety rise to above $80 \%$ by the end of 2015.Thus, the popularity of consumption culture of food safety is an important mean of protecting food safety,let them consciously make it as a weapon to safeguard their rights and interests. On one hand, In the process of food consumption, pay more attention to life, health and physical safety, establish the concepts of scientific and safe consumption, and gradually rose to as consumption culture for safety. On the other hand, constantly innovates contents and forms of propaganda and education of safe consumptions, and vigorously create atmosphere of safe consumption culture, improve awareness of safe consumptions and self-protection capabilities of consumer groups;continuously enhance awareness of the rights protection for university consumer groups, and finally establish a safe consumption culture after long-term precipitation and solidification.

\section{Summary}

Food safety is directly related to health and safety of university consumer groups. Only by strengthening construction of the food safety culture can we build a harmonious and safe campus, offering paths for alternative values and behaviors. Therefore, establishment of food safety culture should be based on human life and health, so as to emphasize material culture, regulatory culture, liability culture, scientific consumption culture, arouses moral conscience and social responsibility of food producers and businessmen, rights-protection of lawabiding and self-protection awareness of health of consumer groups, and strengthen healthy consciousness of scientific supervision and fulfillment of legal responsibilities of regulatory authorities and etc, and provide guidance on the consciousness of technology support and group governance in the society which protect safety of food production and business and order of consumption, forming the social atmosphere of morality, honesty, quality, and health.

Acknowledgments This research was financially supported by Major Program of Education Department of Guangxi Province(200103 YB013).

\section{References:}

[1]Tang Boxing. Attention Should Be Paid to Food Safety Culture Construction. China Pharmaceutical, pp.1-2,2006.

[2] Yu Junlin, Wang Yanlin. Culture Paths of Food Safety Issues. Chinese Business Research, pp.51- 52,2012.

[3] Zhang Bin. Food Enterprises' Subject and Society Responsibility Stipulated in Food Safety Law. Food Industry, pp.6667,2010 .

[4]Schein E H. Organizational culture. American Psychologist,pp.109-119,1990. [5]Yongan Liu. Application of attitude theory in modern management. Journal of Dongguan University of Technology,pp. 46-47,2002.

[6]Wang Meixian, Zhuang Guobo. Harmony Control of Exploring Levels of the Management of Education. Contemporary Youth Research, pp.64-65, 2010. 